\title{
Application of Metrological Approaches in the Design of Calibration Equipment for Verification of Float Level Gauges
}

\author{
L’uboš Kučera ${ }^{1}$, Branislav Patin ${ }^{1}$, Tomáš Gajdošík ${ }^{1}$, Rudolf Palenčár ${ }^{2}$, Jakub Palenčár ${ }^{2}$, Miloš Ujlaky ${ }^{3}$ \\ ${ }^{1}$ University of Žilina, Department of Design and Machine Elements, Faculty of Mechanical Engineering, University of \\ Žilina, Univerzitná 8215/1,01026 Žilina,Slovakia,lubos.kucera@fstroj.uniza.sk \\ ${ }^{2}$ Slovak Technical University of Bratislava, Department of Automation, Measurement and Applied informatics, Faculty of \\ Mechanical Engineering, Namestie slobody 17, 813 21, Bratislava, Slovakia \\ ${ }^{3}$ Slovak Legal Metrology n. o. Banská Bystrica, Hviezdoslavova 31,974 01, Banska Bystrica, Slovakia
}

\begin{abstract}
The paper deals with a scientific approach for an increase of accuracy of measurement and possibilities for automation of the standard equipment for calibration and verification of float level gauges. They are applied in high-capacity fuel storage tanks, and they are intended to measure the level of stored liquid hydrocarbons. In the submitted paper, we describe original approaches towards metrological control of float level gauges. Firstly, we present and describe the current ways of control by means of the standard equipment of the first generation with a precision caliper and manual measuring wire with the application of modern scientific and developing processes. A new system, whose design is based on research and development, represents a fully automated measuring system which utilizes the incremental optical encoder with a precision graduated ring and a rewind pulley. The paper deals with the issue of a design of the standard equipment and its measurement system from the standpoint of metrology and construction. Based on scientific procedures, we solve reasons of errors in measurement and their reduction on concrete components of the measurement system. The result is that, following the scientific approach and mathematical description of the determination of measurement uncertainties, constructors are able to design suitable tolerances for the production of components of measuring devices and related materials and technologies.
\end{abstract}

Keywords: Calibration, verification, accuracy of measurement, precision of measurement, production tolerances, float level gauge, incremental optical encoder.

\section{INTRODUCTION}

In industrial practices there regularly occur requirements for the measurement of a level of media - liquid or bulk materials in storage tanks. Two types of measurement of the level are applied: contact or contactless [23]. A typical example of the contactless measurement is a radar level sensor. A float level gauge is an example of the contact measurement.

Float level gauges belong to a category of specific measuring devices that are verified at regular intervals [1], [2], [23], [21]. Metrological control of float level gauges was carried out strictly only in laboratories. Regarding measuring ranges (the order of tens of meters) and a vertical working position, common laboratory facilities are integrated into towers or shafts constructed for a specific purpose.

Metrological control in the laboratory requires specific facilities and transportation of the gauge that is not always close to its place of work. That results in, from the standpoint of a customer, finding new alternatives of measurement of the level in stationary storage tanks. In order to meet the customer's needs, Slovak Legal Metrology, n.o. (hereinafter referred to as "SLM"), within its research and development activities proposed a solution and in 2015 it launched a new generation of standard equipment for the metrological verification of float level gauges, so-termed $\mathrm{ZOH}$, which enables measurements right on the customers' premises. $(\mathrm{ZOH}-$ the standard equipment for verification of float levelling devices).

In development and design of its prototype, SLM cooperated with scholars from the Faculty of Mechanical Engineering at the University of Žilina. A unique work was the result of long-term experience and theoretical knowledge. The process of development consisted of research of development possibilities and new methods, followed by the identification of affecting factors to define the theoretical model of measurement, quantification of particular sources of measurement uncertainties, definition of parameters and methods of their measurement. Moreover, we defined tasks and principles of particular components in a measuring system from the design, described requirements of accuracy and quality of production. We followed results of prototype production, its testing as well as modifications based on 
experimental results. The final step was validation of the measuring system by its comparison with its reference laboratory represented by the producer Endress\&Hauser in Japan with the aim to meet requirements of the standard EN ISO/IEC 17025 [18].

The paper represents a possibility to connect scientific works with applied principles to develop unique metrological systems. In case that standard construction facilities are not utilized in development, scientific approaches must be applied. Before the construction design, a thorough and detailed analysis of metrological requirements must be performed. It is crucial to know how to work with dimensions, tolerances and available technologies and their real capacities in relation with strict and specific requirements for accuracy as it is in the case of the new generation of the standard equipment for metrological verification of float level gauges.

The paper focuses on the requirement for the measuring system applied to the unique principle of the standard measuring equipment, methodology of measurement, and analysis of the original and new solution of the measuring system. Furthermore, it presents the approach to the definition of production tolerances following metrological requirements.

\section{A. Requirement for calibration and verification of float level gauges}

The design of the measuring system was based on the requirements of the supplement (automatic level gauges) of the Decree of the ÚNMS SR no. 161/2019 Coll. on measuring instruments and metrological control and the requirements of International Recommendation OIML R 85 (ÚNMS - Slovak Office of Standards, Metrology and Testing) [1], [2], [3].

\section{SUBJECT \& METHODS}

\section{A. Current status}

The equipment ZOH1 (the first generation) for calibration and verification of float level gauges was developed based on the utility model no. 166-2013. [5] This measuring system allows very effective verification of the float level meter directly at the customer's premises, without a need for the meter to be transported to the calibration laboratory. Fig.1. presents the scheme of the equipment $\mathrm{ZOH} 1$ for calibration and verification of float level gauges. The equipment consists of a movable pulley (P1) hung on the wire (S2) with the diameter of $0.1475_{-0.0075}^{+0.0075} \mathrm{~mm}$ [4], a tested float level gauge
(S1), a fixed pulley (P2), and a container (2) positioned on the scales (4) filled with liquid (3). A displacer (S3) immersed in the liquid (3) is suspended on the axis of a movable pulley $(\mathrm{P} 1,1)$, a caliper $(5)$ with the measuring range of $330 \mathrm{~mm}$. Fig.2. shows the schematic detail of the measuring component of the standard equipment $\mathrm{ZOH} 1$. The adjusting weighing part consists of a fixed pulley (P3), a movable pulley (P4), and a counterweight (6). The wire (S2) is wound manually on a winding pulley (P5).

To simulate a drop of the level by one step, we need to perform the following operations:

1. To unlock the locking screw and allow a feed of the movable jaw of the caliper.

2. To unlock the movable jaw of the caliper and to displace the open moveable holder to the beginning of the measured distance of the wire.

3. To lock the locking screw.

4. To record the data of the caliper as the beginning of the measured segment $-L_{\mathrm{p}}$.

5. To unlock the fixed screw of the fixed support.

6. To move a wire from left to right up to the point when the movable jaw reaches the end of the measured segment by a slow and smooth motion of the arm of the caliper.

7. To record the data of the caliper as the end of the measured segment - $L_{\mathrm{k}}$.

8. To control a fixation of the displacer in the equilibrium position visually.

9. To lock the fixed screw of the fixed support. 10. To record the data of the level meter, scales and measuring time.

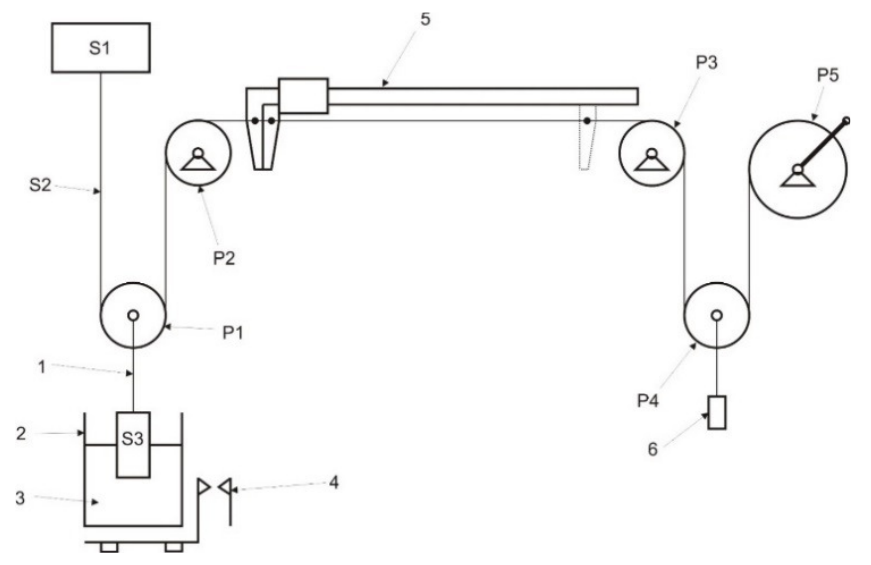

Fig.1. The scheme of the equipment ZOH1.

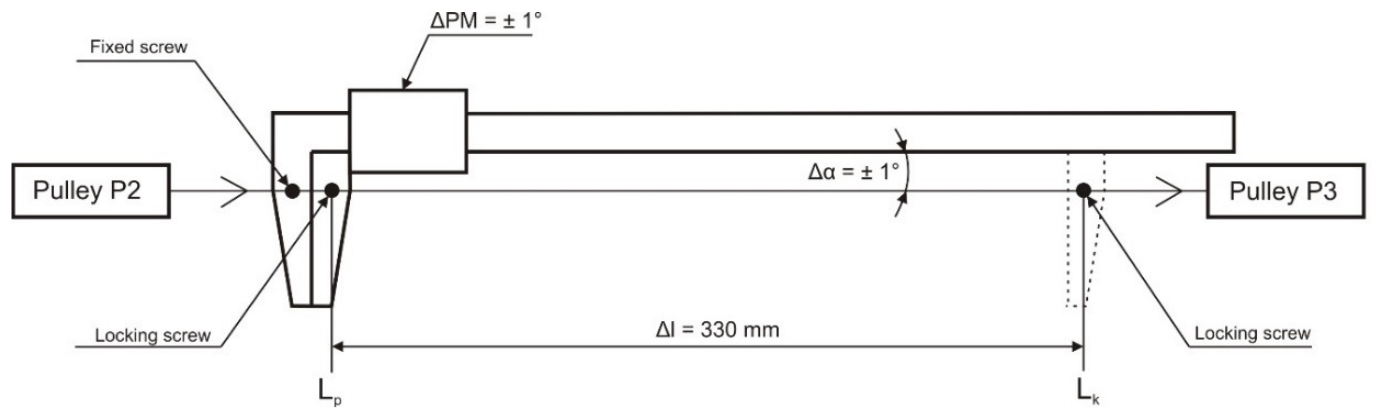

Fig.2. The scheme of the measuring device of the equipment $\mathrm{ZOH} 1$. 
In case of the measuring range of 26 meters of the float level gauge, it is necessary to perform 64 displacements of the wire from point $A$ to point $B$.

In practice, the construction of equipment $\mathrm{ZOH} 1$ consists of the welded L-profiles. A $500 \mathrm{~mm}$ digital caliper (Mitutoyo, type: Absolute Digimatic) with a digital display with the resolution $d_{\mathrm{s}}=0.01 \mathrm{~mm}$ and the maximum permissible error $m p e=0.03 \mathrm{~mm}$ was applied to measure the segment of the length of wire. A portable scale with the capacity of $2 \mathrm{~kg}$ was used to measure the liquid container. To be more specific, it was Mettler Toledo, type EL 2001/01 with the division value $0.1 \mathrm{~g}$ with the maximum permissible error $m p e=0.1 \mathrm{~g}$. The winding of wire was performed manually with an intuitive speed and acceleration. Fig.3. shows the equipment $\mathrm{ZOH} 1$ by the verification of a float level gauge. Then, particular data obtained from measurements are transferred into the evaluating program with final results of measurements via a data cable.

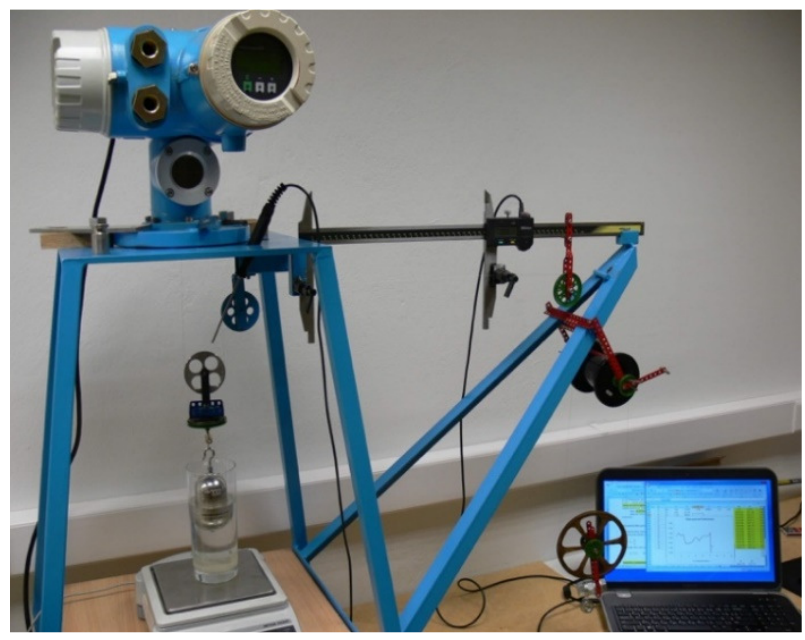

Fig.3. The standard equipment $\mathrm{ZOH} 1$ by verification of a float level gauge.

\section{B. Design of new measuring system}

With the aim to eliminate some adverse effects (they were a part of measurement uncertainty in the original solution), to improve measurement and to prepare a measuring system for the process of automation, we started to design new measuring equipment. The new design is based on the equipment $\mathrm{ZOH} 1$ in order to increase the accuracy of the measurement. Therefore, a measuring component with the caliper is substituted by the incremental optical encoder with a precision graduated ring (Renishaw, type: RESM 20, $n=23,600, d=20 \mu \mathrm{m})$ representing a standard measure of length. [19]. The measurement system provides measurement accuracy of 0.1 arc. sec., it is part of a precision pulley with the diameter $105.2 \pm 0.03 \mathrm{~mm}$, in which the wire is positioned with the wrap angle $360^{\circ}$. The design of the measuring system fully meets the criteria for automation. To be more specific, a stepper electric motor with a gear and a belt drive provides wire winding. As a result, there is no need for any manual interference during measurement. The scheme of the equipment with a new measuring system (the optical encoder with the ring) is shown in Fig.4.

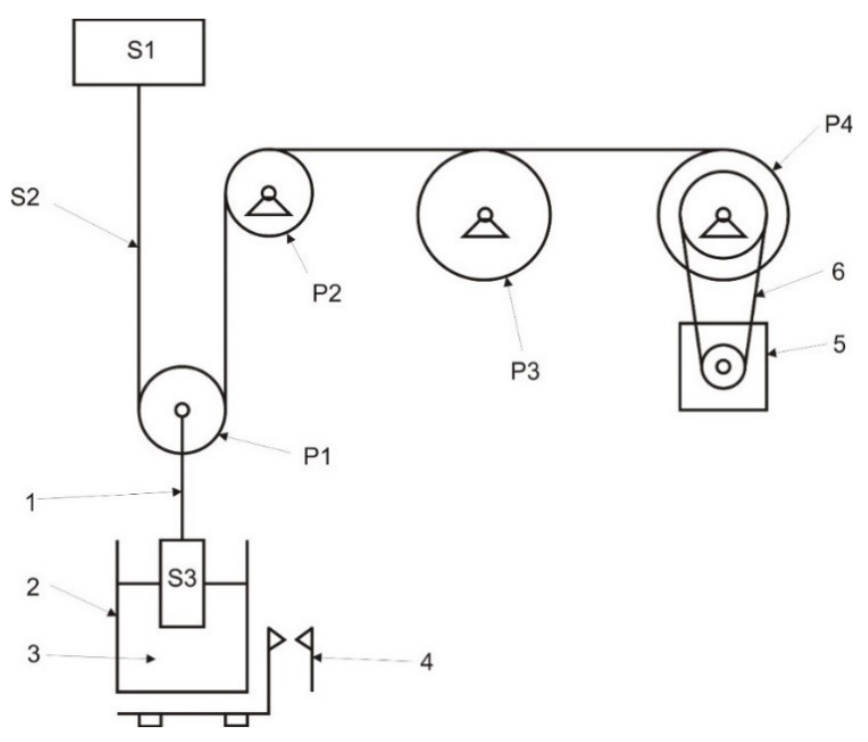

Fig.4. The scheme of the equipment with a new measuring system.

The original solution of the equipment consists of a movable pulley (P1) suspended on the wire (S2) with a diameter of $0.1475_{-0.0075}^{+0.0075} \mathrm{~mm}$, a tested float level gauge (S1), a fixed pulley (P2), a container (2) positioned on the scales (4) and filled with liquid (3). A displacer (S3) immersed in the liquid (3) is suspended on the axis of a movable pulley $(\mathrm{P} 1,1)$. A part of the new measuring system is a precise pulley (P3). A winding pulley is driven by the stepper electric motor with a gear (5) by means of a V-belt or directly without it.

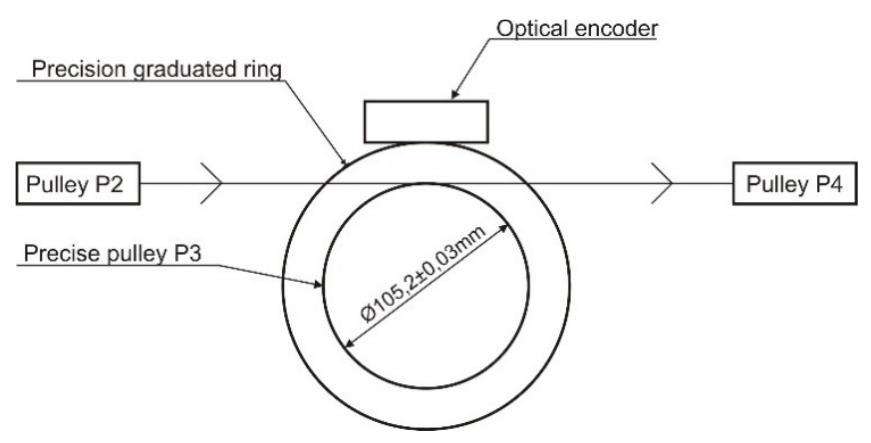

Fig.5. The scheme of the measuring component of the standard equipment.

To simulate a drop of the level by one step, it is necessary to perform one revolution of the measuring pulley. After the revolution, it is important to record the data from the measuring system, the float level gauge and the period of measurement. Fig.6. shows new standard equipment in a verification of the float level gauge. On the left, there is only a manual winding of the rope on the winding pulley. On the right, a stepper electric motor with gear is implemented into the system.

In practice, the construction of the equipment consists of aluminium modular profiles. The stepper motor EMMT-AS60 -L-LS-RMB with the rated power $410 \mathrm{~W}$, the rated speed $3,000 \mathrm{~min}-1$ and torque $1.3 \mathrm{Nm}$, is used as a drive of the 
winding pulley. Furthermore, power transfer and speed change are provided by the planetary gear unit EMGA-60-PG5-EAS-60 with the gear ratio $\mathrm{i}=5$. The motor is controlled by the servo drive CMMT-AS-C2-3A-PN-S1.
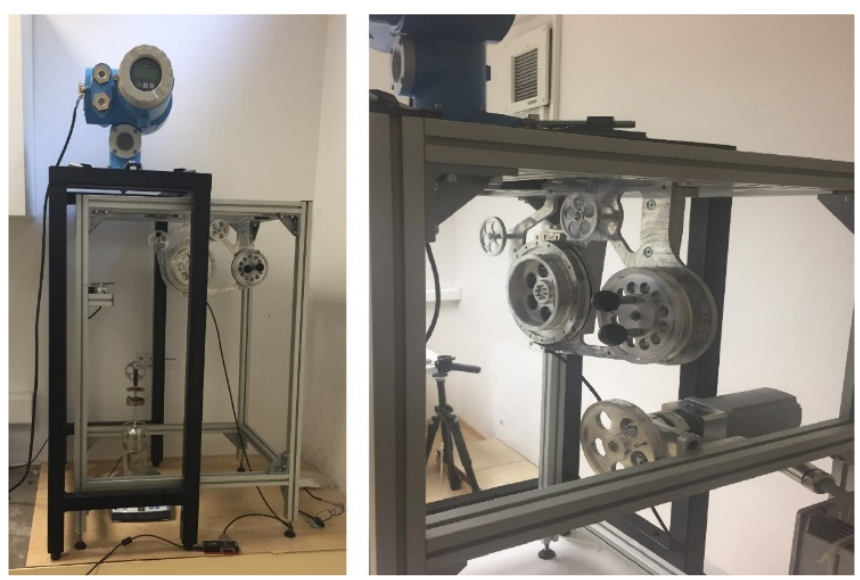

Fig.6. The standard equipment with the new measuring system in a verification of the float level gauge. On the left, with the manual drive. On the right, the system is implemented with a stepper electric motor with a gear.

In design, the drive is based on the analysis of the utilized pulley mechanism. To calculate a minimum torque $M_{\min }$, the formula was applied:

$$
M_{\text {min }}=I_{4} \alpha_{4}+\left[\left(\frac{1}{2} m_{z} g+\frac{I_{2} \alpha_{2}}{r_{2}}+\frac{I_{3} \alpha_{3}}{r_{3}}\right) r_{4}\right] .
$$

Where $I_{4}$ - moment of inertia of the winding pulley P4, $\alpha_{4}-$ angular acceleration of the winding pulley $\mathrm{P} 4, r_{4}$ - radius of the pulley $\mathrm{P} 4, m_{\mathrm{z}}-\mathrm{a}$ weight suspended on the wire $\mathrm{S} 2$, $g$ - gravitational acceleration, $I_{2}$ - moment of inertia of the fixed pulley $\mathrm{P} 2, \alpha_{2}-$ angular acceleration of the winding pulley $\mathrm{P} 2, r_{2}$ - radius of the pulley $\mathrm{P} 2, I_{3}$ - moment of inertia of the measuring pulley P3 with the measuring system, $\alpha_{3}$ angular acceleration of the measuring pulley P3 with the measuring system, $r_{3}$ - radius of the pulley $\mathrm{P} 3$.

A slip of the stepper motor takes place at a certain acceleration by pulling the wire through the pulley or the measuring system. To solve this problem, we followed the Euler-Eytelwein formula. The formula states that maximum acceleration of the stepper motor $a_{\text {max }}$ equals:

$$
\left|a_{\text {max }}\right|=\frac{\frac{r_{3}^{2} m_{z} g}{2 I_{3}}}{\left(\frac{1-e^{f \varphi}}{e^{f \varphi}}-\frac{I_{2} r_{3}^{2}}{I_{3} r_{2}^{2}}\right)}
$$

Where $f$ - friction coefficient, $\varphi$ - wrap angle.

\section{Measurement model and determination of uncertainties}

The main issue of the designed solution is that an error occurs every time while using the new measurement system. The error is caused by an inaccuracy in the production of a pulley groove $(\mathrm{P} 3)$ of the measuring system. The inaccuracy is caused by a permissible tolerance of roundness and roughness of the groove surface [4], [5]. The groove of the measuring pulley in which the wire is placed has the diameter $105.2 \pm 0.03 \mathrm{~mm}$ including the tolerance of roundness $\pm 0.03 \mathrm{~mm}$. The wire diameter is $0.1475_{-0.0075}^{+0.0075} \mathrm{~mm}$. Moreover, a tolerance of the wire of a float gauge also affects an error in measurement. Therefore, for a calculation, we considered geometries of the measuring pulley and its parameters [6], [7], [8]. A wire length, i.e., a length of the measured segment, is determined by a length of a neutral fibre in the wire. As a result, for the calculation of the length of the neutral fiber, a formula for a circle circumference is applied. It is supposed that a position of the neutral fibre varies by a modified diameter of the wire. This results in the fact that the length of the neutral fiber increases with increasing diameter. Fig.7. shows that a circle diameter formed by a wrapped neutral fibre around the pulley $D_{\mathrm{k}}$ equals:

$$
D_{k}=D_{L}+D \text {. }
$$

Where D - nominal dimension of the pulley diameter and $D_{L}$ - nominal dimension of the wire diameter. The wire length and thus one measured segment that unwinds from a wire drum for one revolution of the measuring pulley equals:

$$
L=D_{k} \times \pi
$$

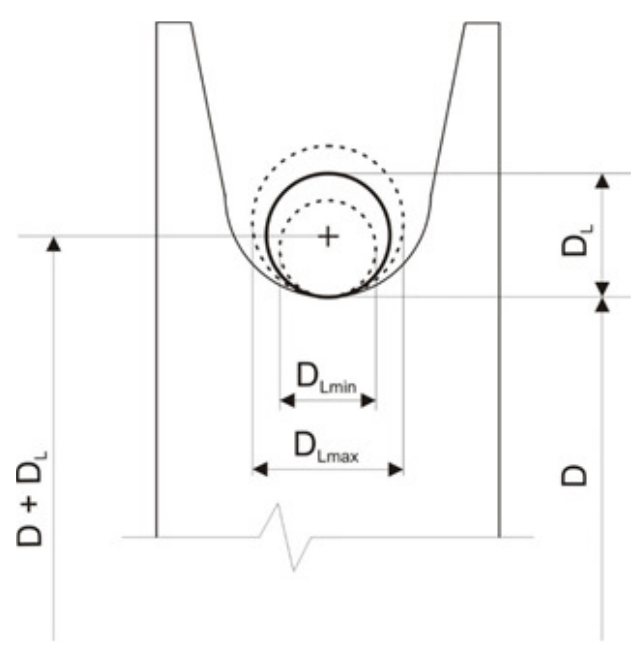

Fig.7. The scheme of the wire placement in the pulley groove.

Fig.7. shows the scheme of the placement of the wire in the groove of the measuring pulley. Where $D_{\mathrm{k}}$ is determined by the relation:

$$
D_{\mathrm{k}}=D+D_{\mathrm{L}}
$$

Where $D$ is a nominal diameter of the pulley and $D_{\mathrm{L}}$ is nominal dimension of the wire diameter.

\section{Uncertainty of Measured Segment}

Standard uncertainty of a wire length per one pulley revolution is:

$$
u(L)=\pi \times u\left(D_{\mathrm{k}}\right)
$$


where standard uncertainty of a pulley diameter, considering the relation (5), is

$$
u^{2}\left(D_{\mathrm{k}}\right)=u^{2}(D)+u^{2}\left(D_{\mathrm{L}}\right)
$$

When we consider that $D_{\mathrm{L}} \in(0.140 ; 0.155) \mathrm{mm}$ will be in case of the normal distribution of an error of wire diameter (we know the bounds with the probability of $95 \%$ ) for an estimation of the wire diameter $\widehat{D_{L}}=0.1475 \mathrm{~mm}$

$$
u\left(D_{\mathrm{L}}\right)=\frac{0,155-0,1475}{2}=\frac{0.0075}{2}=0.00375 \mathrm{~mm} .
$$

The pulley diameter (a groove in which the wire is placed) is designed initially as $D=(105.2 \pm 0.03) \mathrm{mm}$. That means the standard uncertainty of the pulley diameter assuming a balanced diameter distribution is

$$
u(D)=\frac{0.03}{\sqrt{3}}=0.0173 \mathrm{~mm} .
$$

Therefore, the uncertainty of the circle diameter (see relation (6)) for the design of a pulley with the diameter $D=(105.2 \pm 0.03) \mathrm{mm}$ would be

$$
u\left(D_{\mathrm{k}}\right)=\sqrt{0.0173^{2}+0.00375^{2}}=\sqrt{0.000313}=0.0177 \mathrm{~mm} .
$$

In case of 64 revolutions, the uncertainty of the length of the wire (measured segment) is

$$
u(L)=\pi \times 64 \times 0.0177=3.557 \mathrm{~mm} .
$$

Thus, when assuming a normal distribution of the wire length, an expanded uncertainty of the length of a measured segment is

$$
U(L)=2 \times 3,557=7.12 \mathrm{~mm} .
$$

To make an expanded uncertainty of the total measured length $U=1 \mathrm{~mm}$ (which results from the proposal of designed standard equipment), the standard uncertainty must be $u(L)=0.5 \mathrm{~mm}$. Then the standard uncertainty of the length per one revolution

$$
u\left(L_{1 \text { rev }}\right)=\frac{0.5}{64}=0.0078 \mathrm{~mm}
$$

And standard uncertainty of a circle per one revolution

$$
u\left(D_{\mathrm{k}}\right)=\frac{0.0078}{\pi}=0.00248 \mathrm{~mm} .
$$

That means a permissible error (a permissible expanded uncertainty). In the current design, the considered tolerance (expanded uncertainty) of the pulley is $0.03 \mathrm{~mm}$ and tolerance of the wire diameter is 0.0075 , which results in an expanded uncertainty of 0.035 . Therefore, it is necessary to decrease the tolerance of the wire diameter as well as the tolerance of the pulley diameter.

\section{RESULTS}

The result of the work is the new equipment $\mathrm{ZOH} 2$ for verification of float level gauges based on scientific research in the given field. Particular construction components were produced on the basis of requirements for the minimization of measurement error. The equipment is implemented by an automatic drive system of the winding pulley with own SW and HW solution. Therefore, based on the research of uncertainties of measurement and performed calculations of measurement uncertainties, the measuring pulley was produced with the required dimension $(105.2 \pm 0.0012) \mathrm{mm}$ with a wire tolerance of $\pm 0.0042 \mathrm{~mm}$, what represents the uncertainty of a circle according to the relation (7)

$$
u\left(D_{\mathrm{k}}\right)=\sqrt{\left(\frac{0.0012}{\sqrt{3}}\right)^{2}+\left(\frac{0.0042}{2}\right)^{2}}=0.0022 \mathrm{~mm} .
$$

From the standpoint of production technology, it is a very high required accuracy. However, this accuracy can be obtained by modern $\mathrm{CNC}$ machines. As a result, the requirement of an expanded uncertainty of a length of a measured segment of $1 \mathrm{~mm}$ will be met in the production of a measuring pulley plus uncertainty of the wire length.

During calibration of the designed measuring system when determining the resulting measurement uncertainty, it will be necessary to identify and quantify all significant influencing variables, to determine the uncertainty budget on the basis of experimental calibration data, for further uncertainty contributions arising from the conditions of use of the equipment. The purpose of this paper was to introduce a design of the equipment and accuracy of the production of its components (pulley) in terms of an achievable uncertainty of the measuring equipment.

\section{DISCUSSION / CONCLUSIONS}

The analysis of a form of measurement uncertainties was performed by the critical element analysis of the measurement system. Before the construction design, we as constructors did not deal with measurement uncertainties sufficiently enough. The result was an incorrect proposal of tolerances. By an application of scientific knowledge from the field of measurement and statistics, the conditions for minimisation of the impact of pulley dimensions on measurement accuracy were set. A definition of the conditions of tolerance in a proposal of metrological equipment must be obtained by an analysis of measurement uncertainties, a definition of critical elements of the measuring system and, consequently, fields of tolerance of individual components must be formed. The work points to the necessity of the scientific knowledge application from the field of measurement and statistics, even in a pre-construction process, to avoid deficiencies in a construction solution, especially in the initial design. It is a lesson for constructors of metrological devices where to start with the process of construction, and how an insufficient analysis may affect the accuracy of the measurement system. Currently, the equipment is in a test operation. 


\section{ACKNOWLEDGMENT}

This publication is the result of the Project implementation: Competency Centre for Knowledge technologies applied in Innovation of Production Systems in Industry and Services, ITMS: 26220220155, supported by the Research \& Development Operational Programme funded by the ERDF, Project APVV agency: APVV-15-0164, APVV-15-0295, APVV-18-0066 and KEGA Agency: KEGA 014STU$4 / 2020$.

\section{REFERENCES}

[1] (2018). Law of 15. May 2018 on metrology and on amendments to certain laws. In Collection of Laws of the Slovak Republic, 157/2018 Z. z. (in Slovak)

[2] (2019). Decree of the ÚNMS SR of 27. May 2019 on measuring instruments and metrological control. In Collection of Laws of the Slovak Republic, 161/2019 Z. z. (in Slovak)

[3] International Organization of Legal Metrology (OIML). (2008). Automatic level gauges for measuring the level of liquid in stationary storage tanks. Part 1: Metrological and technical requirements. Part 2: Metrological control and tests. OIML R 85-1 \& 2. Edition 2008 (E).

[4] Endress+Hauser Group Services AG. Operating instruction Proservo NMS5. https://portal.endress.com/wa001/dla/5000404/6055/0 00/06/BA00401G08EN08.16.pdf.

[5] Chren, I. (2014). Method and equipment for testing and calibrating float level meters. Utility model SK 6864 Y1. (in Slovak)

[6] Witkovský, V., Wimmer, G., Ďurišová, Z. Ďuriš, S., Palenčár, R. (2017). Brief overview of methods for measurement uncertainty analysis: GUM uncertainty framework, Monte Carlo method, characteristic function approach. In MEASUREMENT 2017: 11th International Conference on Measurement. IEEE, 35-38.

[7] Wimmer, G., Palenčár, R, Witkovský, V., Ďuriš, S. (2015). Evaluation of Calibration the Measuring Instruments: Statistical Methods for the Analysis of Uncertainties in Metrology. Bratislava, Slovak Republic: Slovak Technical University. (in Slovak)

[8] Witkovský, V., Wimmer, G. (2018). Generalized polynomial comparative calibration: Parameter estimation and applications. In Advances in Measurements and Instrumentation: Reviews, Vol. 1. International Frequency Sensor Association (IFSA) Publishing, 15-52.

[9] Wimmer, G, Witkovský, V. (2019). Twodimensional linear comparative calibration and measurement uncertainty. In MEASUREMENT 2019: 12th International Conference on Measurement. IEEE, 66-69.

[10] Witkovský, V., Wimmer, G., Ďurišová, Z., Ďuriš, S., Palenčár, R., Palenčár, J. (2018). Modeling and evaluating the distribution of the output quantity in measurement models with copula dependent input quantities. In Advanced Mathematical and
Computational Tools in Metrology and Testing XI. World Scientific Publishing Company, 409-416.

[11] Joint Committee for Guides in Metrology (JCGM). (2008). Evaluation of measurement data - Guide to the expression of uncertainty in measurement. JCGM 100:2008 (GUM 1995 with minor corrections).

[12] Joint Committee for Guides in Metrology (JCGM). (2011). Evaluation of measurement data - Supplement 2 to the "Guide to the expression of uncertainty in measurement" - Extension to any number of output quantities. JCGM 102: 2011.

[13] Duriš, S., Palenčár, R. (2006). The influence of covariances on the uncertainty of temperature measurement by resistance thermometer. Measurement Science Review, 6 (3), 34-38.

[14] Ďuriš, S., Palenčár, R., Ranostaj, J. (2008). Contribution of the SPRT calibration to uncertainty of temperature T90 measured by the calibrated SPRT. Measurement Science Review, 8 (1), 5-10.

[15] Palencar, R., Duris, S., Brdecka, R. (2000). Contribution to the evaluation of the uncertainties of the SPRT calibration in the defining fixed points. In Comité consultative de thermométrie / Consultative Committee for Thermometry (CCT): 20th Meeting. BIPM, CCT/2000-23.

[16] Joint Committee for Guides in Metrology (JCGM). (2008). International vocabulary of metrology - Basic and general concepts and associated terms (VIM), 3rd edition). JCGM 200:2012 (2008 version with minor corrections).

[17] Sopkuliak. P., Palenčár, R., Palenčár, J., Suroviak, E., Markovič, J. (2017). Evaluation of uncertainties of ITS90 by Monte Carlo Method. In Cybernetics and Mathematics Applications in Intelligent Systems: 6th Computer Science On-line Conference (CSOC2017). Springer, vol. 2, 46-56.

[18] International Organization for Standardization (ISO). (2005). General requirements for the competence of testing and calibration laboratories. ISO/ EIC 17025.

[19] Klapetek, P. (2005). Verification and calibration of level meters in the Czech Republic. Automa - Magazine for Automation Technology, (5). (in Czech)

[20] Valle, B.S. What is level? http://benvalle.com/Level.html.

[21] Kučera, L', Markovič, J., Chren, I. (2014). Measuring system for calibration and verification of radar level gauges. Metrológia a skúšobníctvo, 19 (1), 21-25. (in Slovak)

[22] Lipták, G.B., Venczel, K. (eds.). (2016). Measurement and Safety: Volume I. (5th edition). CRC Press.

[23] Mikuš, P. (2016). Environmental impact on accuracy and reproducibility of distance measurements at radar level meters. Dissertation thesis, STU Bratislava, Slovakia. (in Slovak)

Received July 13, 2020 Accepted October 12, 2020 